\title{
The economics of scientific publication: Introduction
}

\author{
Esther-Mirjam Sent and Arjo Klamer
}

\begin{abstract}
Whereas methodological discussions of scientific publication frequently occur in an institutional vacuum, in the sense that they take little account of the process whereby scientific contributions are published, this symposium illuminates the urgency of focusing on the increased dominance of commercial considerations in scientific publication in particular and science in general. It stresses the importance of embarking upon a multi-disciplinary evaluation that starts from a contextual perspective, looks at developments in sciences other than just economics, and goes beyond attributing everything to technological changes.
\end{abstract}

Keywords: publishing, science, serials crisis, monographcrisis, economics of science

Publish or perish ... perhaps the reality of the academic rat race is not quite as grim as suggested by this cliche, but publishing does constitute an important activity in our scientific lives. As the same time, the world of publishing shows a stark contrast between surplus and shortage. Each year publishers begin new monograph series yet the libraries are unable to accommodate the increasing supply. Some publishers are cutting back while others enthusiastically embrace whichever book proposal makes it their way. Many manuscripts find eager purchasers in Asia while American and European academics' budgets do not allow them to buy these books. Scientists seeking journal outlets for their research are witnessing an increase in publishing possibilities. At the same time, their piles of articles to be read are cluttering their offices in a more and more alarming manner. Moreover, librarians' budgets are not growing at the same pace as the number and prices of journals.

Whereas methodological discussions of scientific publication frequently occur in an institutional vacuum, in the sense that they take little account of the process whereby scientific contributions are published, this minisymposium illuminates the urgency of focusing on the increased dominance of commercial considerations in scientific publication in particular and science in general. The developments outlined above have given rise to the so-called serials and monograph crises. The former refers to the mismatch between journal prices and library budgets. The latter describes decreased 
publishing possibilities for academic books as well as an increased focus on profit-making. And these developments are a reflection of wider changes that have been occurring in the general structure, organization, and funding of science. Before discussing these changes, let us illustrate the mounting strains and tensions within the world of scientific publication through a few stories.

Consider the flurry of lawsuits filed by the Gordon and Breach Publishing Group against the American Institute of Physics and the American Physical Society. The litigation concerned the rights of professional societies, who are themselves publishers, to prepare and print comparative price data for journals. The trouble started when Henry Barschall, a physics professor at the University of Wisconsin at Madison, conducted a study comparing the prices of physics journals that appeared in both Physics Today (Barschall 1988), which is the journal of the American Institute of Physics, and the Bulletin of the American Physical Society (Barschall and Arrington 1988), which, as its name suggests, is published under auspices of the American Physical Society. Barschall's study found that the journals published by Gordon and Breach had the highest average cost per character as well as the highest average ratio of cost to impact. It concluded that journals of scientific societies, such as the American Institute of Physics and the American Physical Society, are more cost-effective than those of commercial publishers. Gordon and Breach filed a lawsuit charging a flawed methodology, a skewed choice of journals, and incomplete research. A lower court dismissed the case, ruling that the two societies appearing as defendants in the lawsuit had not engaged in unfair competition. A federal appeals court upheld the decision, based on the argument that the articles were constitutionally protected free speech. This was not the end of the societies' legal hassles, for Gordon and Breach also filed lawsuits charging false comparative advertising in countries in which this is illegal, namely Germany, Switzerland, and France. The cases were dismissed in Germany and Switzerland, but the one in France is still pending the settlement of the estate of Henry Barschall, who passed away amidst all the legal battles. The plot thickens when it was discovered that Gordon and Breach had used stationary belonging to the Foundation for International Scientific Cooperation for a survey sent to university libraries asking them whether they had canceled journal subscriptions because of Barschall's reports. This prompted the Association of Research Libraries to send a memorandum to its members informing them that the survey could be used to assess damages for future litigation. In fact, the Association had itself issued a report on journal prices in which Gordon and Breach publications were found to be among the most expensive. Yet, the result of the publisher's actions and threats has been to deter librarians and others from engaging in additional analyses of the costs of scholarly journals. For instance, libel lawsuit threats issued by Gordon and Breach led the American Mathematical Society to exclude Gordon and Breach from several of its surveys of the costs for mathematical journals. When the society did 
include the publisher's numbers in one of the surveys that appeared in Notices of the American Mathematical Society, Gordon and Breach, as we may expect by now, demanded a retraction and investigated litigation possibilities. It went as far as criticizing the results in a two-page advertisement with the heading 'AMS Continues Gross Distortions in Surveys; Abrogates Agreement with Gordon and Breach' (Gordon and Breach 1990).

Now, the previous story is certainly not an isolated affair, for it is easy to find other stories such as the following. The players in this one are Elsevier, the Association for Logic Programming, and the Journal of Logic Programming (Bergstra 2000; Birman 2000). Upon its foundation in 1986, the Association for Logic Programming adopted the then 2-year-old Journal of Logic Programming, which was published by Elsevier, as its 'house journal'. In the beginning libraries paid $\$ 0.28$ per page for their subscription; by 1999 this price had gone up to $\$ 0.88$ per page (Birman 2000). While the consumer price index increased roughly 44 per cent over the period of a decade, the price charged to libraries went up about 158 per cent over the same period. This prompted Krzysztof Apt, the president of the Association for Logic Programming, and Maurice Bruynooghe, the editor-in-chief of the Journal of Logic Programming, to enter into negotiations with Elsevier over the price of library subscriptions. Elsevier did not renege, arguing that it offers libraries attractive package deals and many additional services. The 16-month negotiations came to an abrupt end when Bruynooghe resigned as editorin-chief and was followed by the entire fifty-member editorial board. They all moved to Cambridge University Press to found a new house journal for the Association for Logic Programming, Theory and Practice of Logic Programming, with a subscription price of 45 per cent of the old price. Elsevier continued its journal under a new name, Journal of Logic and Algebraic Programming, and with a new editorial team. It then accused the Association for Logic Programming of frustrating its attempts to keep the journal going by discouraging its members from joining the editorial board. In a final twist to this narrative, the $2000 \mathrm{P}-\mathrm{A}-\mathrm{M}$ Award of the Physics-AstronomyMathematics Division of the Special Libraries Association recognized Bruynooghe, his editorial board, and the Association for Logic Programming for acknowledging the problems that increasing journal costs cause for both libraries and scholars, and for taking steps within their own scholarly community to effect positive change. Again, this story is not an isolated incident.

In 1999, the editor and editorial board of Evolutionary Ecology, a journal published by Kluwer, resigned to start Evolutionary Ecology Research, which became solely their intellectual and financial responsibility (Rosenzweig 1999). Evolutionary Ecology was first published in 1984 by Chapman \& Hall, with Michael Rosenzweig as its originator as well as editor-in-chief. In 1987, Chapman \& Hall suffered a hostile takeover by the International Thomson Corporation. Eleven years later, the publisher was sold to Kluwer. 
All along, the hapless editor watched the subscription price of his brainchild go up and up. Rosenzweig (1999) estimated that in 1998 the cost of producing and distributing Evolutionary Ecology was less than $\$ 80,000$, whereas subscription revenues were somewhere between $\$ 250,000$ and $\$ 300,000$, amounting to a 275 per cent markup, or a 73.3 per cent profit margin. Rosenzweig decided that enough was enough and begged and pleaded with Kluwer to sell the journal to a university press, but to no avail. The editor and his editorial board decided to jump ship and start Evolutionary Ecology Research, with the support of SPARC, the Scholarly Publishing and Academic Resources Coalition. They lowered the subscription price for a combination of hard copy and Internet access from $\$ 800$ to $\$ 305$. They also offered an Internet subscription for \$272, an option that had not been available for Evolutionary Ecology. The new journal's website (http://www.evolutionary-ecology.com) offers the following clarification on pricing: 'As a SPARC partner, we are trying to help reduce the high prices of commercial journals. Each page of EER costs a library that subscribes less than $\$ 0.26$ (US). That's a price that many thought became extinct with the dinosaurs! It is less than half the price often charged for similar scientific journals'.

Now, the commercialization evidenced by the narratives so far has certainly not remained isolated to the publication of journals by commercial presses (Thatcher 1990; Winkler 1997; Collier 1999; Schriffrin 1999). In fact, the so-called serials crisis was preceded by what has been labeled the monograph crisis. For instance, Andre Schriffrin, managing director of Pantheon Books, which was known for focusing on cultural rather than economic value in its publication decisions, was forced to resign by Random House, the corporate parent of Pantheon Books, for having run up large losses for too long. At the same time, university presses, which used to be supported by their host universities, are increasingly expected to make financial contributions to their hosts. Combined with cost increases, a more and more monopolistic market as a result of the concentration of ownership of publishing houses, an increasingly monopsonistic market due to declining library purchases, and the concentration of bookstore ownership, these developments are making it nearly impossible for the presses to continue publishing as many monographs. For instance, Oxford University Press has decided to stop publishing contemporary poetry as well as several imprints and series. Rutgers University Press discontinued the publication of scholarly monographs with low expected sales. Louisiana State University Press focuses on popular novels such as its Confederacy of Dunces. The shift from culture to profit, from small academic audiences to large commercial ones, or from specialized scholarly monographs to popular trade books has been so widespread and alarming that the Association of American University Presses, sponsored by the Andrew W. Mellon Foundation, is currently conducting a 4-year study of the monograph crisis. 
We could fill an entire issue of the Journal of Economic Methodology with further frightening illustrations of the monograph and serials crises, but would then be doing you a disservice. Instead, we believe it is important to stress that the situation in which scientific publication currently finds itself is representative of changes that have been taking place in the general structure, organization, and funding of science. What the world of scientific publication in particular and academia in general are witnessing is a shift from the 'Cold War regime' to the so-called globalized privatization regime (Sent 1999; Mirowski and Sent 2002). In the process, the military-university complex has been superseded by an industry-university connection, the protection of 'pure science' has been replaced by a desire to make money, and the freedom of information supposedly characterizing science has been threatened by efforts to commodify knowledge. It comes as no surprise, then, that the structure, organization, and funding of scientific publication are changing along with the shift to the new regime. In our opinion, these transitions are much more significant that any presumed information revolution (Standage 1998). With the end of the cold war, the decline in military funding, the hostility towards government interference, skepticism about the telos of science, questions about the accountability of science, and the push to develop connections between business and science, the monograph and serials crises could not lag far behind.

These events must cause those interested in the economics of scientific publication to confront at least four sets of issues. First, studies of the economics of scientific publication that focus exclusively on the individual incentives of the various actors involved in the process cannot but provide a very limited perspective on developments in the world of scientific publication (Gans 2000). The same holds for statistical analyses of citation patterns and the like that also ignore the importance of contextual changes (Gans 2000). Second, we may consider the publication of books and journals as a topic in industrial organization (Machlup 1962; Berg 1972; Ordover and Willig 1978; Machlup and Leeson 1980). The question then is whether the rise of printing and new means of communication affect the form and content of science (Eisenstein 1979; Standage 1998). There is a serious possibility that bias towards short-term tangible results, often complained about in modern corporate business, may also become increasingly rife in science. Such a foreshortening of the research horizon may result in duplicative publications, anomie, and so forth. Third, differing social and economic structures of science may lead to different forms of scientific journals, influencing submission and page charges (Barton 1963), forms of refereeing (Chubin and Hacket 1990; Cicchetti 1991), rejection rates (Beyer 1978; Hargens 1988), variations in joint authorship (Gans 2000), publication delays, and genre formats. Finally, there is an increasing interest in the potential impacts of electronic publication upon the industry (Day 1993) and upon science (Nunberg 1993), as well as in pricing the Internet (MacKie-Mason and 
Varian 1995). Yet, we remain skeptical as to the size of the impact of these digital developments.

A mini-symposium on the economics of scientific publication does not allow us to provide a comprehensive survey of the events in and literature on the monograph and serials crises, but it does enable us to stress the importance of embarking upon a multi-disciplinary evaluation that starts from a contextual perspective, looks at developments in sciences other than just economics, and goes beyond attributing everything to technological changes. The contributions following this introduction, which were the products of a workshop on the economics of scientific publication, serve to make these points. First, John Mackenzie Owen, an information science scholar, carefully describes the changing context in which the dissemination of knowledge takes place, in the hope that economists will provide theoretical and empirical interpretations of these developments. His paper, 'The new dissemination of knowledge', argues that the traditional information chain is no longer valid due to: (1) a focus on the part of publishers on shareholder value; (2) attempts at self-publication by the academic world; (3) the loss of functional specialization in the information chain; and (4) initiatives to develop digital libraries. As a result, Mackenzie Owen argues, the dissemination of knowledge will transition from physical, printed information resources to networked, digital ones, while publishers and libraries will move from a product-orientation to a focus on service. The next paper, 'Attention and the art of scientific publishing', written by Arjo Klamer, a cultural studies expert, and Hendrik van Dalen, an economic policy advisor, continues the multi-disciplinary focus. It starts with the observation of two harsh facts: (1) there is an inflation in the number of publications; and (2) there is a skewed distribution of attention over all publications. Though these could be understood through the use of a basic market approach or a winner-take-all model, Klamer and Van Dalen make a convincing case for viewing science as a network in which the actors' efforts at competing for attention lead to clustering. And this development will only be stimulated further as a result of digitalization. The contexts outlined in the first two papers receive theoretical treatments in the last two. Robert Parks suggests why one solution to the serials crisis, namely freely available electronic journals (FAEJs), is not a viable alternative to the current subscription, site license, or pay-per-view (S/SL/PPV) model. According to Parks, reasons for changing the S/SL/PPV model include: (1) readership is limited; and (2) costs are escalating. Yet, the incentives of authors, editors, referees, readers, librarians, university administrators, and publishers serve as obstacles in a possible transition from the S/SL/PPV model to the FAEJ one. This is what Parks labels 'The Faustian grip of academic publishing'. Henk Plasmeijer, finally, has a less dismal view of ways out of the serials crisis, though using insights from the dismal science. Careful scrutiny of the market for serials, Plasmeijer argues, shows that the problems occur on the demand side of the market, with demand functions being inelastic and rotating 
clockwise, thereby causing price increases. According to 'Pricing the serials library' solutions may be found in increasing cost awareness on the part of consumers as well as providing additional incentives for cost reduction on the part of libraries.

Obviously, economists have a role to play in evaluating scientific publication. At the same time, several concerns ought to be considered carefully. First, studies limiting themselves to discussions of the incentives of individual scientists, to statistical summaries of the existing situation, or to the effects of technologies changes fail to capture the complexity of the monograph and serials crises and therefore become useless for policy purposes. At the same time, contextual evaluations must confront the effects on the content of science. Second, economists cannot narrow their focus to developments within their own discipline if they desire to play a role in shaping the institutions that constitute science as a whole. This ostrich mentality is reflected by the fact that whereas the serials crisis, which has affected economics, has received some attention from economists, the monograph one, which has hit mostly the humanities, has met with little to no interest in our discipline. Not only will economists have nothing to say about the publication problems affecting science in general, but also will they need to confront the possible pitfalls of reflextivity if they ignore other sciences. Third, economists wanting to employ metaphors such as the marketplace of ideas need to present a convincing argument for engaging in such analyses. After all, there are many possible configurations of the connections between science and the market. Finally, economists must be careful not to raise the suspicion that studies of the economics of scientific publication are part of an imperialistic trend that includes economic analyses of health, marriage, the law, and so on. Too much research in many fields has been done in regards to the publishing phenomenon for economists to be able to get away with that.

We do not mean to discourage our readers from embarking upon economic studies of scientific publication, for we would not have edited this minisymposium if that is how we felt. The monograph and serials crises have reached such alarming depths that an economic analysis of these events is urgently needed. As long as the caveats outlined here are carefully considered, economists ought to be able to make valuable contributions to the understanding of scientific publication.

Esther-Mirjam Sent and Arjo Klamer
University of Notre Dame and
Erasmus University, Rotterdam
sent.2@ndu.edu/klamer@fhk.eur.nl

\section{REFERENCES}

Barschall, Henry H. (1988) 'The cost effectiveness of physics journals', Physics Today 41: 56-9. 
Barschall, Henry H. (1989) 'The cost effectiveness of physics journals', Physics Today 42: $15,154$.

Barschall, Henry H. and Arrington, John R. (1988) 'Cost of physics journals: A survey', Bulletin of the American Physical Society 33: 1437-47.

Barton, Henry (1963) 'The publication charge plan in physics journals', Physics Today 16: 45-57.

Berg, Sanford (1972) 'An economic analysis of the demand for scientific journals', Journal of the American Society for Information Science 23: 23-29.

Bergstra, Jan (2000) 'On the business ethics of commercial scientific publication: A recent case', Working Paper, Informatics Institute, University of Amsterdam and Department of Philosophy, Utrecht University.

Beyer, Janice (1978) 'Editorial policies and practices among leading journals in four scientific fields', Sociological Quarterly 19: 68-88.

Birman, Joan S. (2000) 'Scientific publishing: A mathematician'sviewpoint', Notices of the American Mathematical Society 47: 770-4.

Chubin, Daryl E. and Hackett, Edward J. (1990) Peerless Science, Albany: SUNY Press.

Cicchetti, Domenic (1991) 'The reliability of peer review for manuscript and grant submissions', Behavioral and Brain Sciences 14: 119-86.

Cole, Stephen, Cole, Jonathan R. and Simon, Gary A. (1981) 'Chance and consensus in peer review', Science 214: 881-6.

Collier, Bonnie (1999) 'Preserving the central role of the monograph', Chronicle of Higher Education, 5 February: A56.

Day, Colin (1993) 'Economics of electronic publishing', Paper presented at the AAUP/ ARL Symposium on Electronic Publishing, http://www.press.umich.edu/jep/works/ colin.econ.html

Eisenstein, Elizabeth (1979) The Printing Press as an Agent of Change, New York: Cambridge University Press.

Ford, Kenneth W. and Lubkin, Gloria B. (1988) 'Statement', Physics Today 41: 9.

Ford, Kenneth W. and Lubkin, Gloria B. (1989) 'Statement', Physics Today 42: 13.

Gans, Joshua (ed.) (2000) Publishing Economics: Analyses of the Academic Journal Market in Economics, Cheltenham, UK: Edward Elgar.

Gordon and Breach (1990) 'AMS continues gross distortion in surveys; Abrogates agreement with Gordon and Breach', Notices of the American Mathematical Society 37: $92-3$.

Hargens, Lowell L. (1988) 'Scholarly consensus and journal rejection rates', American Sociological Review 53: 139-51.

Hargens, Lowell L. (1990a) 'Neglected considerations in the analysis of agreement among journal referees', Scientometrics 19: 91-106.

Hargens, Lowell L. (1990b) 'Variation in journal peer-review systems: Possible causes and consequences', Journal of the American Medical Association 263: 1348-52.

Jaco, William (1990) 'Journal price survey - threatened', Notices of the Americal Mathematical Society 37: 2, 18.

Lovell, Michael C. (1973) 'The production of economic literature: An interpretation', Journal of Economic Literature 11: 27-55.

Machlup, Fritz (1962) The Production and Distribution of Knowledge in the United States, Princeton: Princeton University Press.

Machlup, Fritz and Leeson, K. (1980) Information through the Printed Word, New York: Praeger.

MacKie-Mason, Jeffrey K. and Varian, Hal R. (1995) 'Pricing the internet', in Brian Kahin and James Keller (eds) Public Access to the Internet, Cambridge, MA: MIT Press, pp. 269-314. 
Mason, Paul M, Steagall, Jeffrey W. and Fabritius, Michael M. (1992) 'Publication delays in articles in economics: What to do about them', Applied Economics 24: 859-74.

Mirowski, Philip and Sent, Esther-Mirjam (2002) 'Introduction', in Philip Mirowksi and Esther-Mirjam Sent (eds) Science Bought and Sold: Essays in the Economics of Science, Chicago: University of Chicago Press, pp. 1-68.

Nunberg, Geoffrey (1993) 'The place of books in an age of electronic reproduction', Representations 42: 13-37.

Ordover, Janusz and Willig, Robert (1978) 'On the optimal provision of journals qua sometimes shared goods', American Economic Review 68: 324-38.

Rosenzweig, Michael L. (1999) 'Reclaiming what we own: Expanding competition in scholarly publishing', Plenary Address to the Ninth Conference of the Association of College and Research Libraries (http://www.evolutionary-ecology.com/citizen/ reclaiming.html).

Schiffrin, Andre (1999) 'Payback time: University presses as profit centers', Chronicle of Higher Education, 18 June: B4.

Sent, Esther-Mirjam (1999) 'Economics of science: Survey and suggestions', Journal of Economic Methodology 6: 95-124.

Standage, Tom (1998) The Victorian Internet: The Remarkable Story of the Telegraph and the Nineteenth Century's On-line Pioneers, New York: Walker and Co.

Thatcher, Sanford (1990) 'Scholarly monographs may be the ultimate victims of the upheavals in trade publishing', Chronicle of Higher Education, 10 October.

Winkler, Karen J. (1997) 'Scholars assess the health and the value of specialized monographs', Chronicle of Higher Education, 29 September. 